\title{
Materials Characterisation by Nuclear Quadrupole Interaction
}

\author{
T.J. Bastow \\ Division of Materials Science and Technology, CSIRO, Locked Bag 33, Clayton, \\ Victoria 3168, Australia
}

Z. Naturforsch. 49a, 320-328 (1994); received August 31, 1993

\begin{abstract}
The power of solid state NMR to characterise solids by determining the nuclear quadrupole coupling of the constituent nuclei is demonstrated for a number of compounds of current interest in a materials science laboratory. Recent results are presented for the nuclei ${ }^{17} \mathrm{O},{ }^{23} \mathrm{Na},{ }^{27} \mathrm{Al},{ }^{39} \mathrm{~K}$, ${ }^{71} \mathrm{Ga},{ }^{91} \mathrm{Zr},{ }^{93} \mathrm{Nb}$, and ${ }^{139} \mathrm{La}$. These were derived using a variety of FT NMR techniques including static, magic angle spinning and frequency stepped spin echo NMR spectroscopy.
\end{abstract}

Key words: Materials; Nuclear quadrupole interaction; Multinuclear NMR; NQR, Materials characterisation.

\section{Introduction}

In the field of materials science NMR has become a technique for characterising solids almost as widespread as the diffraction methods. Traditionally the isotropic chemical shift has been the main identifier. Recently attention has shifted to the nuclear quadrupole interaction as providing good characterisation for materials containing nuclei with spin $I>1 / 2$. With the present generation of high field spectrometers, nuclear quadrupole interactions can be measured by NMR which were previously considered to be only obtainable by NQR. A specific advantage of NMR over pure NQR for spin $I=3 / 2$ is that the NMR spectrum yields both the coupling constant $\left(C_{q}\right)$ and the asymmetry parameter $(\eta)$ as opposed to the single parameter $v_{1 / 2,3 / 2}=(1 / 2) C_{q}\left(1+\eta^{2} / 3\right)$ measured by NQR.

Spectra are usually obtained by the usual pulsed Fourier transform methods, both static and magic angle spinning (MAS). However, the recent NMR work on high $T_{c}$ superconductors has served as a reminder to the general NMR community that spectra from the heavier nuclei, where the linewidths are of order $1-10 \mathrm{MHz}$, can be obtained from frequency stepped spin echoes.

Presented at the XIIth International Symposium on Nuclear Quadrupole Resonance, Zürich, July 19-23, 1993.

Reprint requests to Prof. Dr. T. J. Bastow, CSIRO Div. of Mat. Science and Technology, Normanby Road Locked Bag 33, Clayton Vic. 3168, Australia.
Some recent results from the author's laboratory, mainly derived from quadrupole perturbed NMR, are presented for the nuclei ${ }^{17} \mathrm{O},{ }^{23} \mathrm{Na},{ }^{27} \mathrm{Al},{ }^{39} \mathrm{~K},{ }^{71} \mathrm{Ga}$, ${ }^{91} \mathrm{Zr},{ }^{93} \mathrm{Nb}$, and ${ }^{139} \mathrm{La}$, exemplifying the usefulness of the nuclear quadrupole interaction as a materials characteriser.

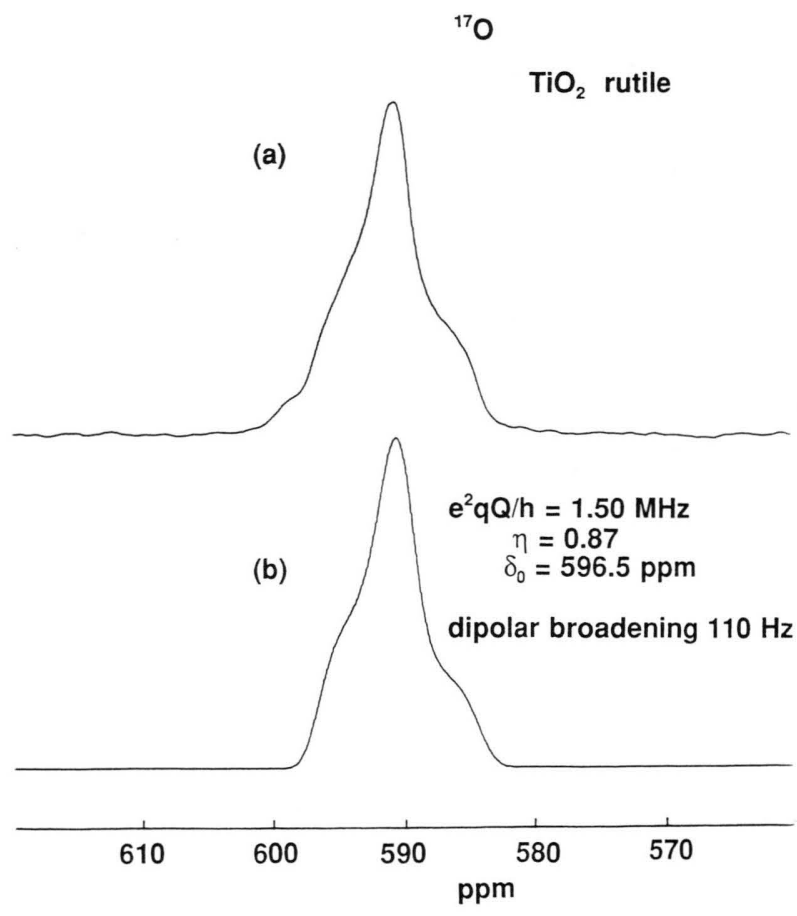

Fig. 1. (a) ${ }^{17} \mathrm{O}$ MAS NMR line shape for the rutile form of $\mathrm{TiO}_{2} ;$ (b) simulated spectrum and quadrupole and chemical shift parameters. 


\section{Experimental}

Spectra were taken on a Bruker MSL 400 NMR spectrometer in a field of $9.4 \mathrm{~T}$ at $296 \mathrm{~K}$. MAS spectra were taken with sample rotation speeds of either $4.5 \mathrm{kHz}\left({ }^{17} \mathrm{O}\right)$ or between 12 and $16 \mathrm{kHz}\left({ }^{23} \mathrm{Na}\right.$ and $\left.{ }^{27} \mathrm{Al}\right)$. The nuclear quadrupole parameters, $C_{q}\left(=\mathrm{e}^{2} q Q / h\right)$ and $\eta$ were obtained by spectral simulation using the Bruker program POWDER, and proceeded by trial and error, varying $C_{q}$ and $\eta$ until a best fit was obtained. The speed and accuracy of this process depend on the quality (i.e. signal-to-noise and

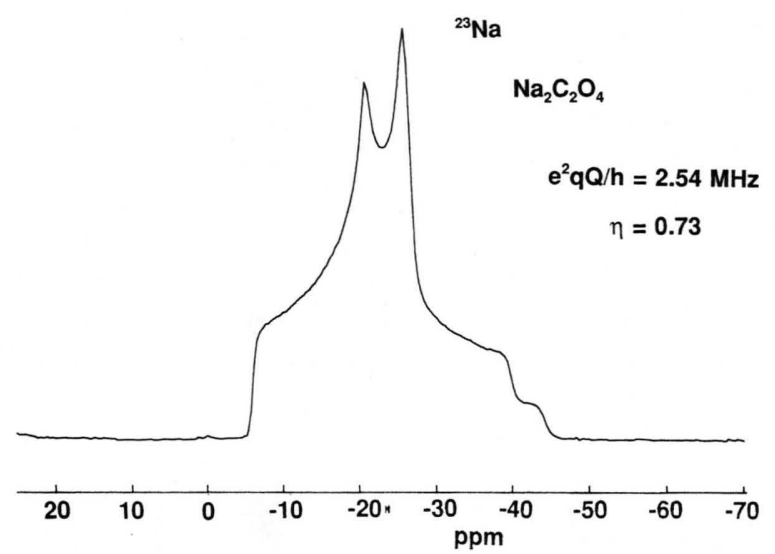

Fig. 2. ${ }^{23} \mathrm{Na}$ MAS NMR line shape for $\mathrm{Na}_{2} \mathrm{C}_{2} \mathrm{O}_{4}$ with simulated spectrum and quadrupole parameters.

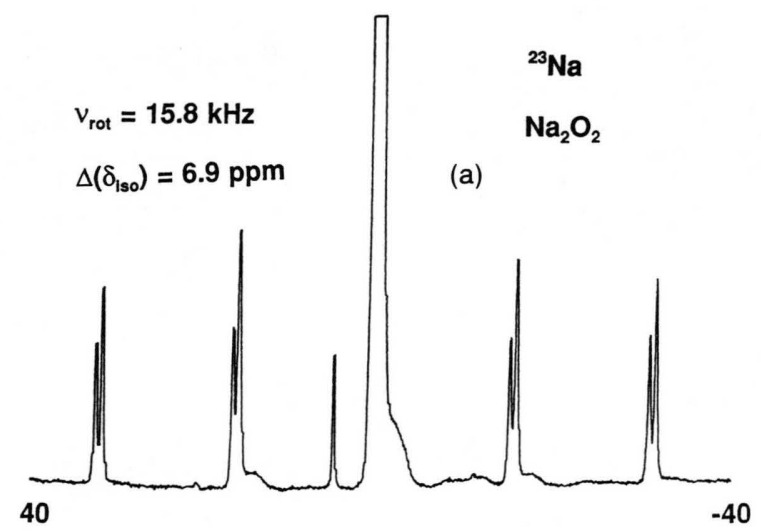

Fig. 3. ${ }^{23} \mathrm{Na}$ MAS NMR spectrum for $\mathrm{Na}_{2} \mathrm{O}_{2} ;$ (a) inner spinning sidebands of the $(-3 / 2,-1 / 2)$ and $(1 / 2,3 / 2)$ satellite transitions, (b) second order broadened $(-1 / 2,1 / 2)$ transitions, (c) full spinning sideband pattern of the satellite transitions with the sidebands of the two sites only barely resolved in the display, (d) plot of the peak heights of the spinning sidebands $-(\mathrm{x})$ the high frequency site, $(\mathrm{o})$ the low frequency site.
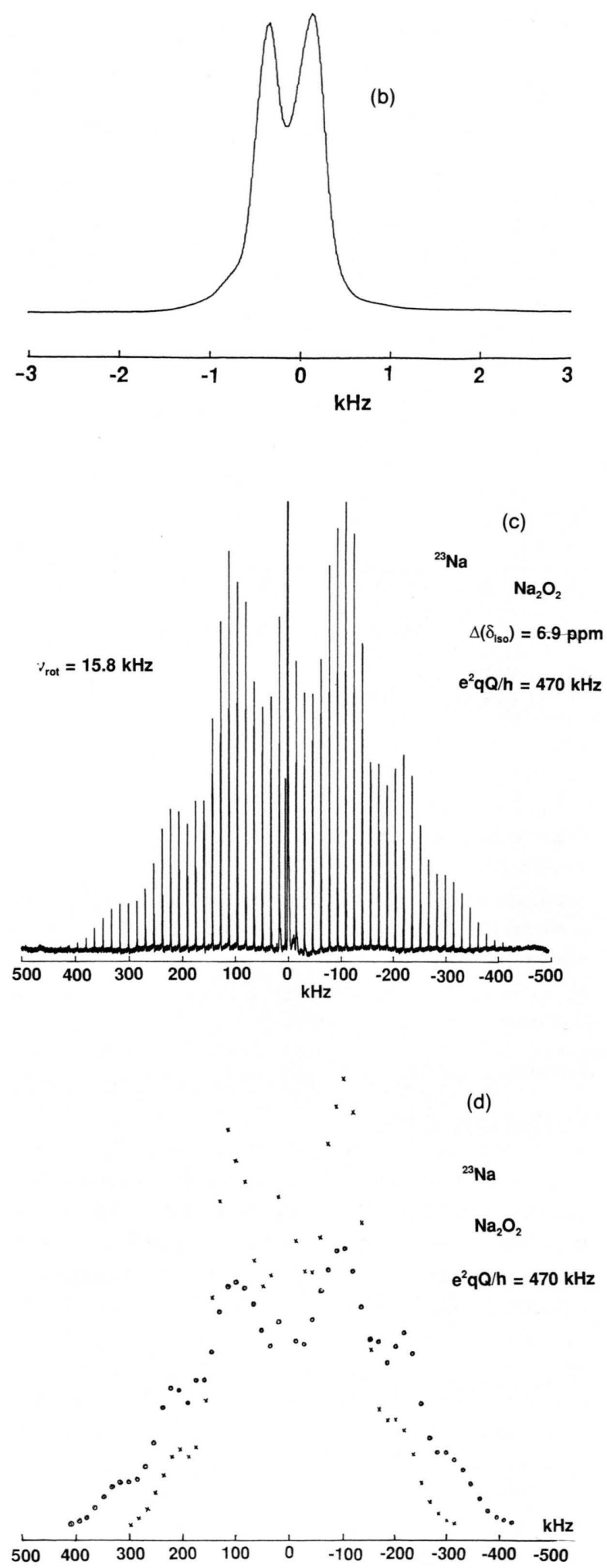


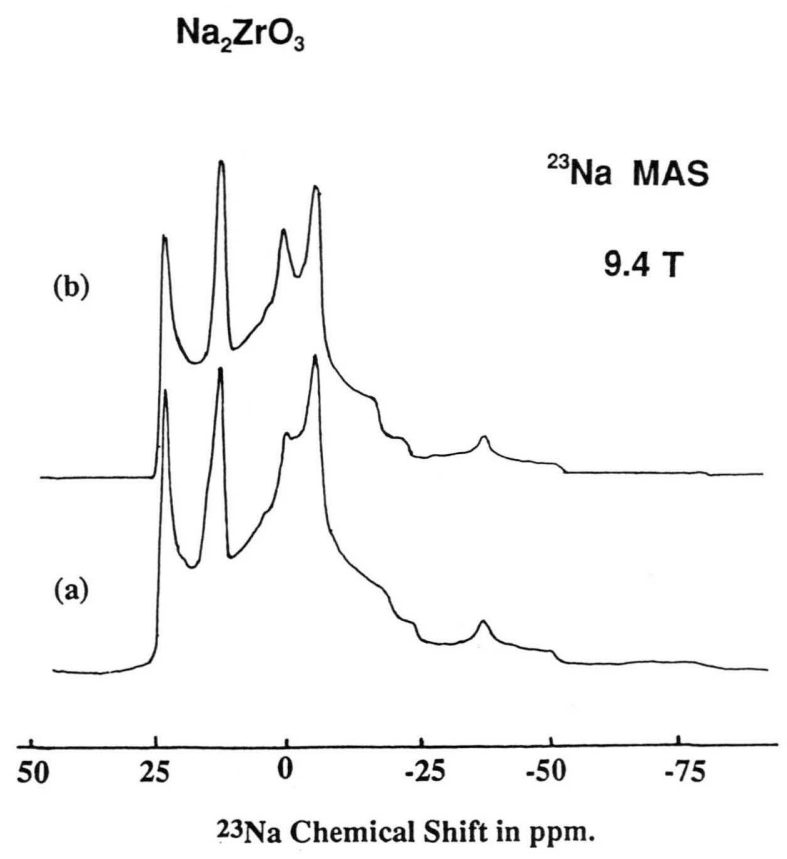

Fig. 4. ${ }^{23} \mathrm{Na}$ MAS NMR spectrum for $\mathrm{Na}_{2} \mathrm{ZrO}_{3}$; (a) observed spectrum, (b) simulated total spectrum.

definition) of the spectrum. In the MAS spectra presented here the $C_{q}$ and $\eta$ values are estimated to be accurate to better than $5 \%$. For the static spectra the error in these quantities range from better than $5 \%$ to about $10 \%$.

\section{Results}

${ }^{17} \mathrm{O}(I=5 / 2)$

Sol-gel methods for producing novel or high density ceramic products often require a knowledge of the local structure of initial poorly crystallised phases which are essentially amorphous to powder X-ray diffraction methods. MAS ${ }^{17} \mathrm{O}$ NMR has been used to identify these early stages in the formation of $\mathrm{ZrO}_{2}$ and $\mathrm{TiO}_{2}$ prepared using the sol-gel process [1-3]. For the $\mathrm{TiO}_{2}$ gel heated to $1000^{\circ} \mathrm{C}$ the nuclear quadrupole parameters, $C_{q}\left(=e^{2} q Q / h\right)$ and $\eta$, derived from simulation of the powder spectrum derived from MAS NMR agree closely with the single crystal results for rutile [4]. Figure 1 shows the measured and simulated spectra.

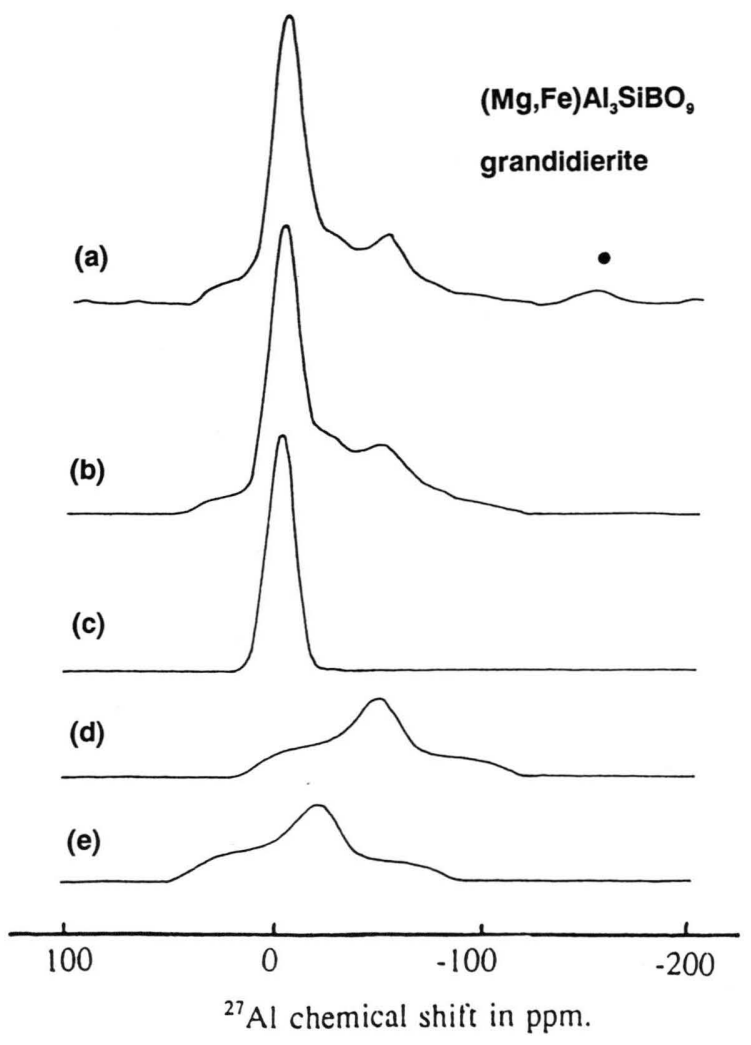

Fig. 5. ${ }^{27} \mathrm{Al}$ MAS NMR spectrum of the boroaluminosilicate mineral grandidierite $(\mathrm{Mg}, \mathrm{Fe}) \mathrm{Al}_{3} \mathrm{SiBo}_{9}$; (a) experimental spectrum of $(-1 / 2,1 / 2)$ transitions, (b) simulation of complete spectrum of $(-1 / 2,1 / 2)$ transitions, (c), (d), and (e) simulation of the component spectra for the sites $\mathrm{Al}(1), \mathrm{Al}(2)$ and $\mathrm{Al}(3)$ respectively.

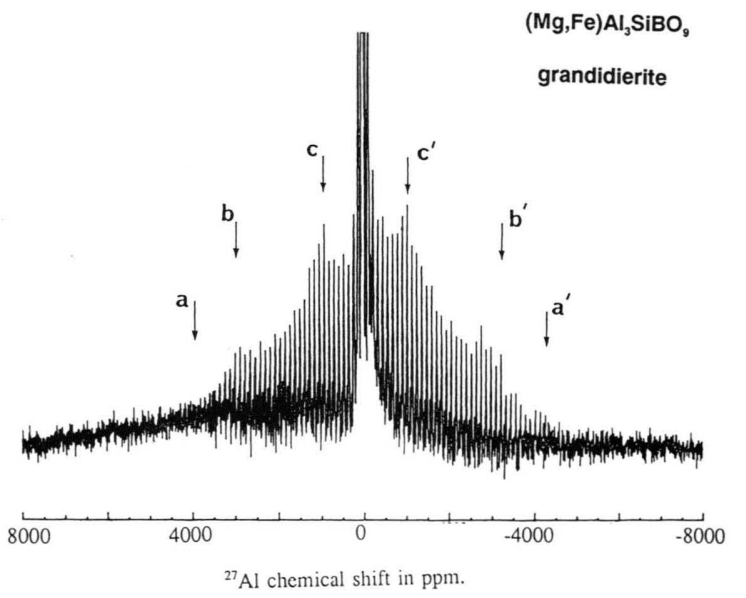

Fig. 6. ${ }^{27} \mathrm{Al}$ MAS NMR spectrum of the boroaluminosilicate mineral grandidierite $(\mathrm{Mg}, \mathrm{Fe}) \mathrm{Al}_{3} \mathrm{SiBo}_{9}$ showing the spinning sideband manifold over ca. $2 \mathrm{MHz}$. The symbols $\downarrow$ indicate proposed singularities in sideband envelope from which $C_{q}$ and $\eta$ for $\mathrm{Al}(1)$ can be determined (see [6]). 

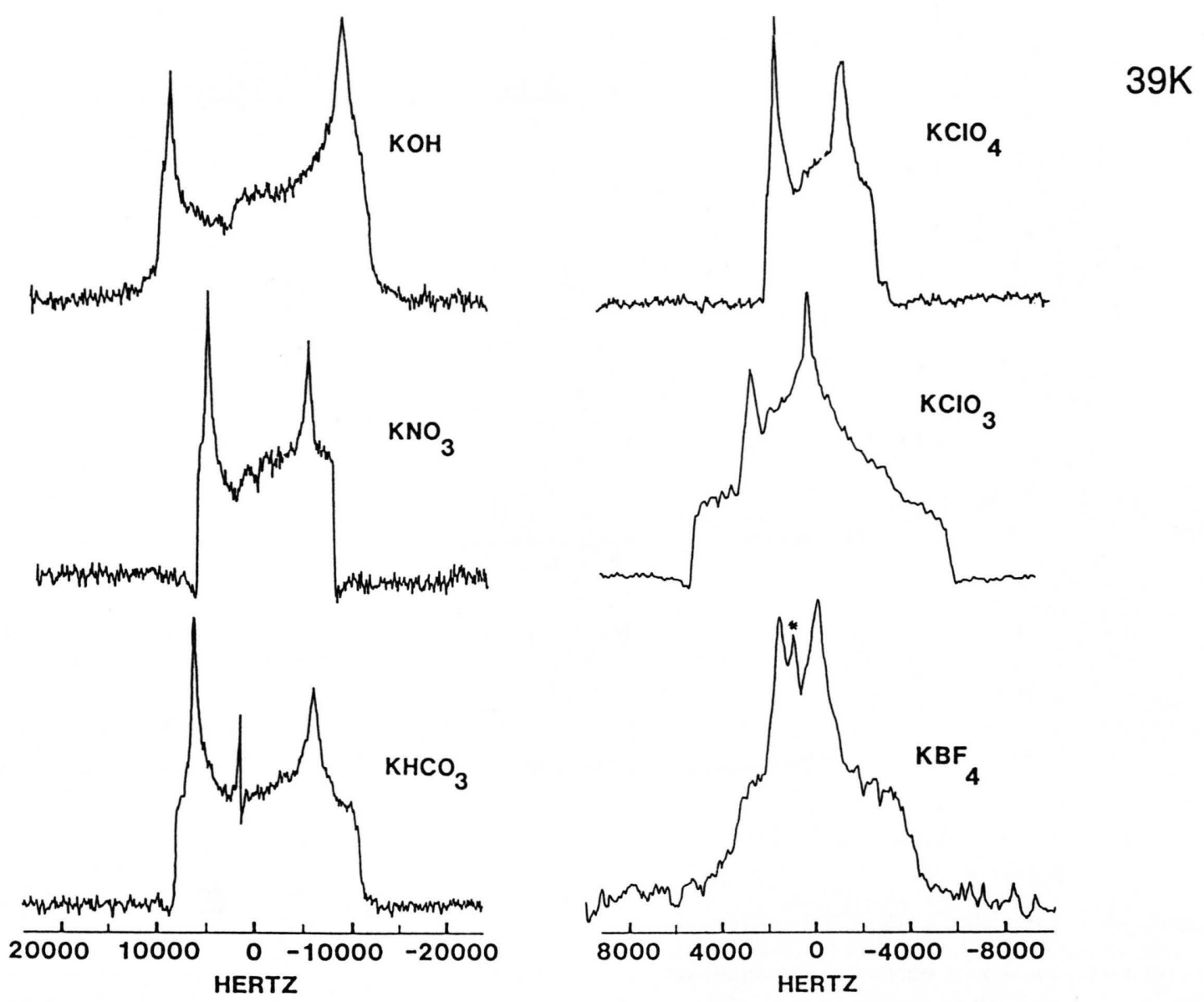

Fig. 7. Lineshapes for the ${ }^{39} \mathrm{~K}(-1 / 2,1 / 2)$ transition for six inorganic potassium compounds with a single $\mathrm{K}$ atom per unit cell in a position of non-axial symmetry. For details see [7].

${ }^{23} \mathrm{Na}(I=3 / 2)$

A textbook example of an MAS second order quadrupole perturbed NMR lineshape is provided by sodium oxalate $\left(\mathrm{Na}_{2} \mathrm{C}_{2} \mathrm{O}_{4}\right)$ and shown in Figure 2 . The values of $C_{q}$ and $\eta$ can be determined easily to an accuracy of about $1 \%$. Sodium peroxide $\left(\mathrm{Na}_{2} \mathrm{O}_{2}\right)$ provides an example where there exist two $\mathrm{Na}$ sites (Fig. 3 a) with axial symmetry and almost equal coupling constants (Figure $3 \mathrm{c}, \mathrm{d}$ ). Here the magnitude of the coupling is such that it is best evaluated from the first order powder pattern (Fig. 3c) which is delineated by the spinning sidebands. Figure $3 \mathrm{~d}$ disentagles the overlapping spinning sideband pattern for each site to show the near equivalence of the two coupling constants. In this example identification of the quadrupole parameters from the second order splitting for the central transition of the two sites is confused by the small chemical shift difference between the sites and the magnitude of the dipolar broadening (Figure $3 \mathrm{~b}$ ). For sodium zirconate, $\mathrm{Na}_{2} \mathrm{ZrO}_{3}$, and $\mathrm{NMR}$ characterisation has recently been completed using the nuclei ${ }^{23} \mathrm{Na},{ }^{17} \mathrm{O}$, and ${ }^{91} \mathrm{Zr}$ [3]. The ${ }^{23} \mathrm{Na}$ MAS spectrum (Fig. 4a) can be decomposed into three (second order) quadrupole perturbed lines with intensity ratios in agreement with the 2:1:1 site occupancies given by the X-ray structure. The simulated spectrum is given in (Figure $4 \mathrm{~b}$ ). The nuclear quadrupole coupling constant $\left(C_{q}\right)$ and asymmetry parameter $(\eta)$ for each site can thus be cleanly determined [3]. 


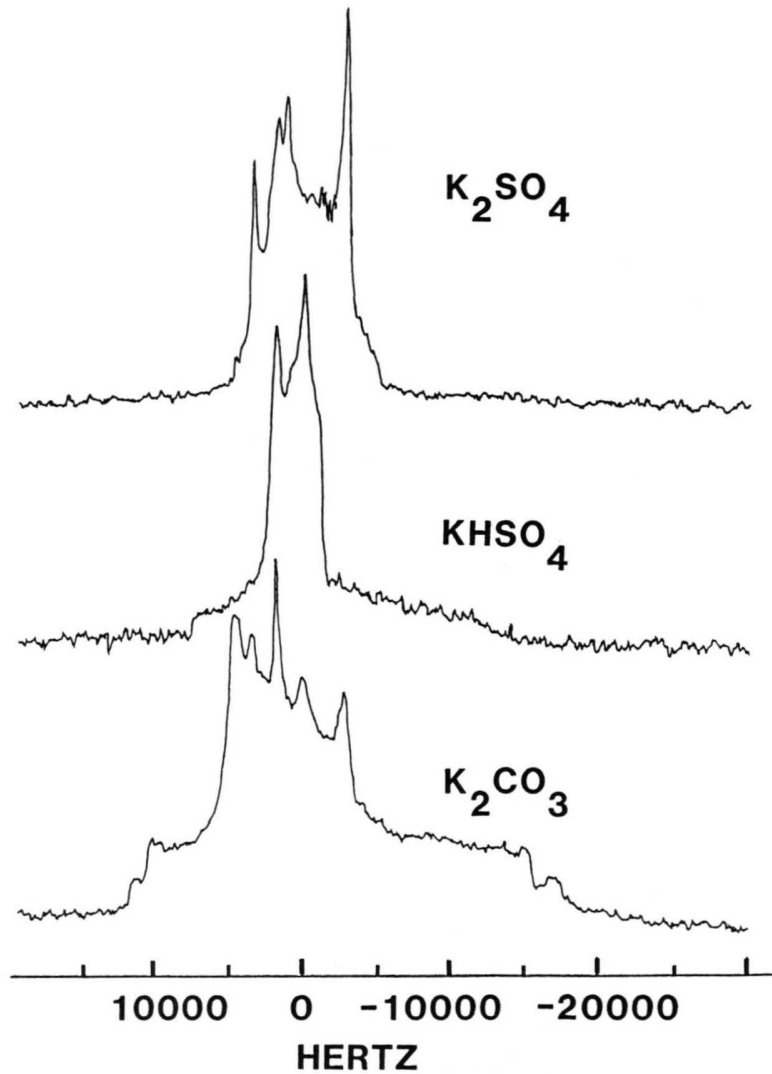

Fig. 8. Lineshapes for the ${ }^{39} \mathrm{~K}(-1 / 2,1 / 2)$ transition for three inorganic potassium compounds with two $\mathrm{K}$ atoms per unit cell in positions of non-axial symmetry. For details see [7].

\section{${ }^{27} \mathrm{Al}(I=5 / 2)$}

The MAS technique provides a fast and powerful method of identifying a large number of aluminium compounds from their NMR spectra [5]. Quadrupolar and chemical shift $(\delta)$ parameters can be obtained by spectrum simulation. The parameter $\delta$ can be used to identify the Al site as being 4, 5 or 6 -fold coordinated by the relevant anion (e.g. $\mathrm{O}$ or $\mathrm{N}$ ). The boroaluminosilicate grandidierite, where one of the aluminium atoms $(\mathrm{Al}(3))$ is 5-fold coordinated, has recently been so characterised [6]. The ${ }^{27} \mathrm{Al}$ MAS spectrum was decomposed into three well defined quadrupolar lines with integrated intensities consistent with their X-ray structure site occupancies. The $C_{q}$ and $\eta$ values for two of the sites $(\mathrm{Al}(2)$ and $\mathrm{Al}(3)$ were determined from their second order spectra (Fig. 5), while those for the third site $(\mathrm{Al}(1))$, with low $C_{q}$, were determined from the first order pattern (Figure 6).

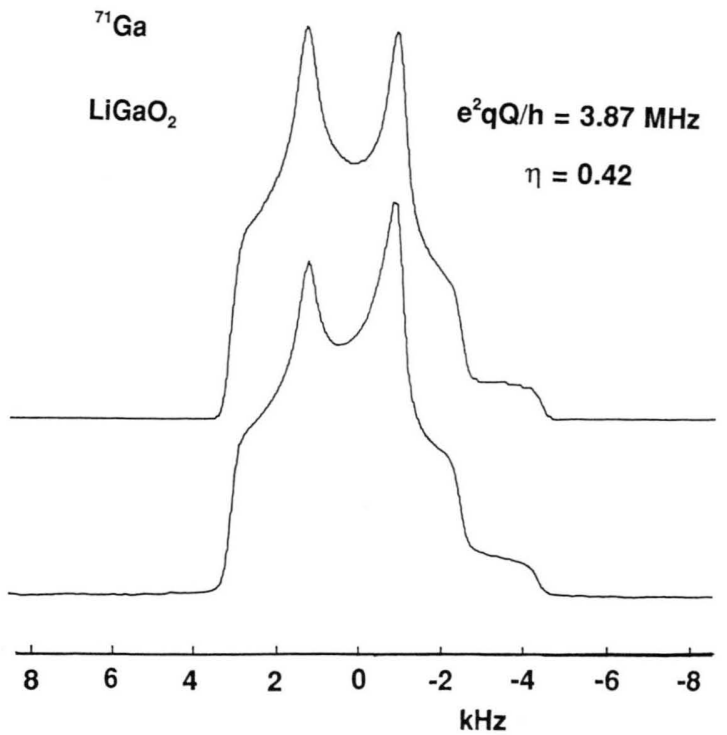

Fig. 9. ${ }^{71} \mathrm{Ga}$ MAS NMR lineshape for $\mathrm{LiGaO}_{2}$; (a) observed lineshape, (b) simulated lineshape with $C_{q}$ and $\eta$ values.

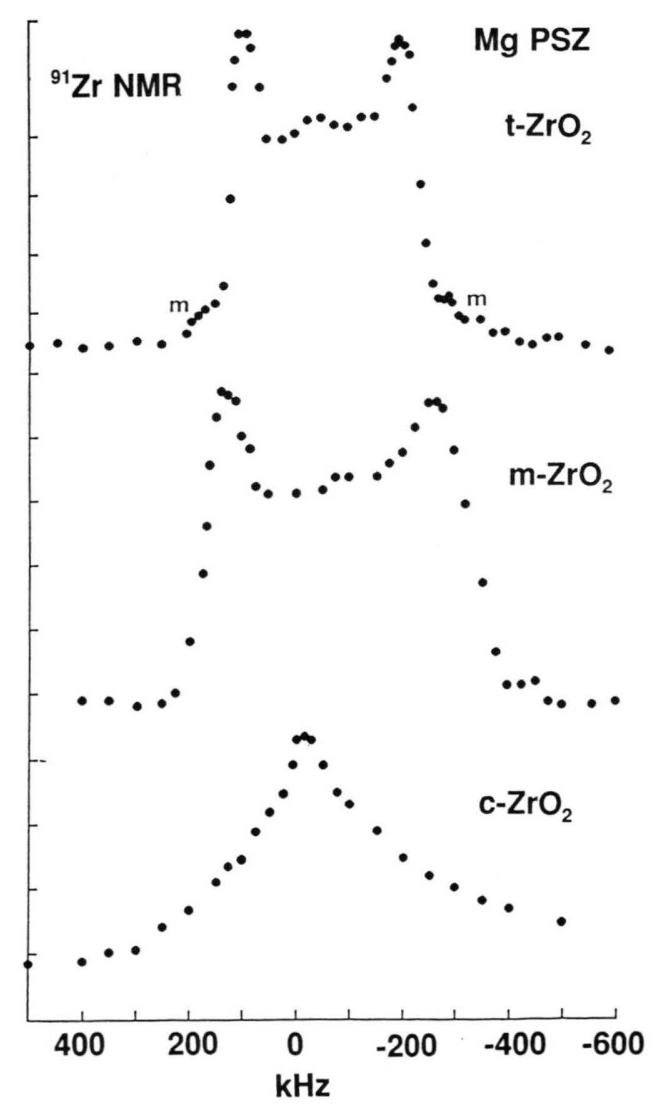

Fig. 10. ${ }^{91} \mathrm{Zr}$ frequency-stepped spin echo NMR lineshape for the $(-1 / 2,1 / 2)$ transition of tetragonal $(\mathrm{t})$, monoclinic $(\mathrm{m})$ and cubic (c) $\mathrm{ZrO}_{2}$. For details see [11]. 


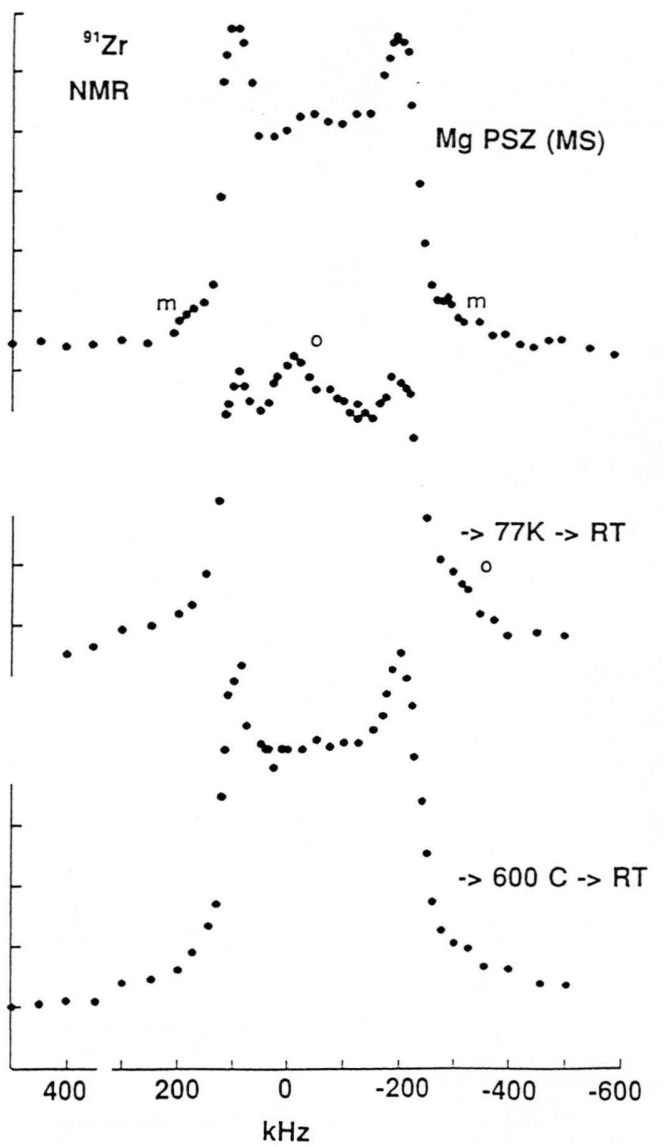

Fig. 11. ${ }^{91} \mathrm{Zr}$ frequency-stepped spin echo NMR lineshape for the $(-1 / 2,1 / 2)$ transition of tetragonal $\mathrm{ZrO}_{2}$ in a sample of partially stabilised zirconia (PSZ): after cooling to $77 \mathrm{~K}$ and warming to $296 \mathrm{~K}$ to exhibit partial transformation to the orthorhombic (o) phase; after heating to $600^{\circ} \mathrm{C}$ and cooling to $296 \mathrm{~K}$ to reverse the transformation. For details see [11].

\section{${ }^{39} \mathrm{~K}(I=3 / 2)$}

The low Larmor frequency of ${ }^{39} \mathrm{~K}$, together with a range of $C_{q}$ values of up to $2 \mathrm{MHz}$, results in lineshapes that are not conveniently measured by MAS. The nuclear quadrupole interaction parameters, derived from the second order quadrupole perturbed lineshape for a static sample obtained using a solid echo, have been shown to provide sharp characterisation of a number of inorganic potassium compounds [7]. Figure 7 displays spectra for compounds chosen to have a single $\mathrm{K}$ site and non zero site asymmetry. The spectra are sharply defined because the

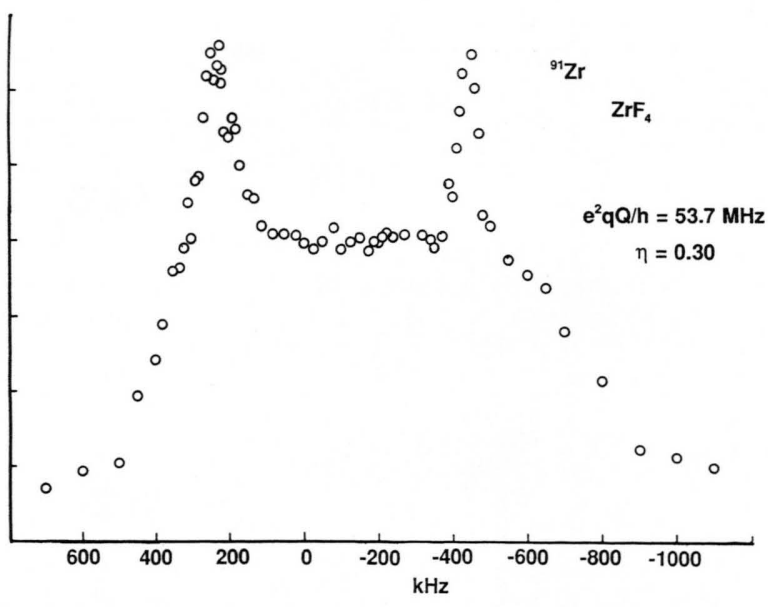

Fig. 12. ${ }^{91} \mathrm{Zr}$ frequency-stepped spin echo lineshape for the $(-1 / 2,1 / 2)$ transition of $\mathrm{ZrF}_{4}$.

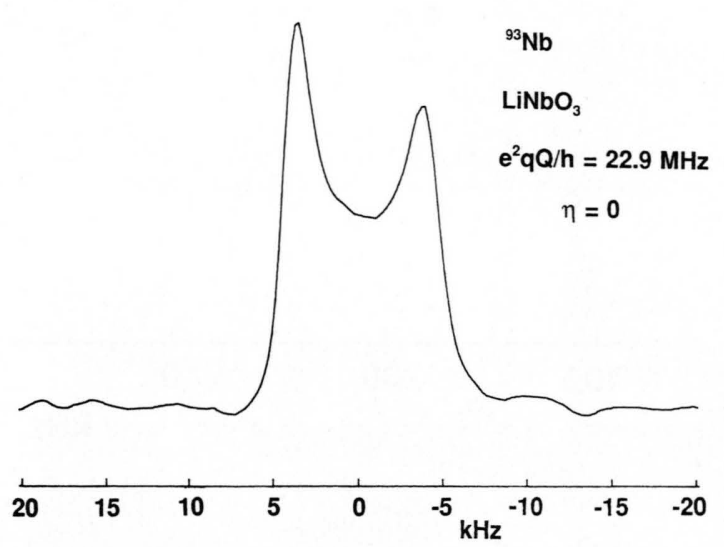

Fig. 13. ${ }^{93} \mathrm{Nb}$ MAS NMR lineshape for the perovskite $\mathrm{LiNbO}_{3}$.

low value of the ${ }^{39} \mathrm{~K}$ magnetic moment yields only small dipolar broadening. Spectra for three compounds with two inequivalent $\mathrm{K}$ sites are shown in Figure 8. The spectrum for $\mathrm{KHSO}_{4}$ is interesting in that previous ${ }^{39} \mathrm{~K} /{ }^{1} \mathrm{H}$ NQR double resonance experiments $[8,9]$ have detected the site with the larger $C_{q}$ but not the site with the smaller $C_{q}$, which is observed here in clear detail. Although the intrinsic precision is somewhat smaller than for NQR double or single resonance, NMR yields both $C_{q}$ and $\eta$, and does not require the close proximity to the $\mathrm{K}$ of a sensitive $I=1 / 2$ nucleus such as ${ }^{1} \mathrm{H}$. 
o

${ }^{139} \mathrm{La}$

$\begin{array}{lll} & 0 \\ \mathrm{La}_{2} \mathrm{O}_{3} & \\ & \circ \quad \text { (a) }\end{array}$

o

○

○ $(-1 / 2,1 / 2) \quad 0$

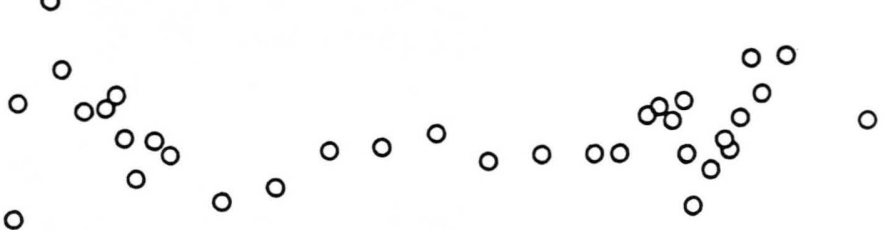

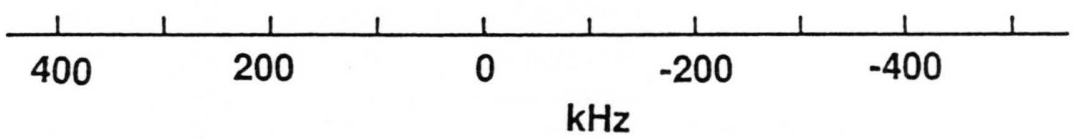

0

o

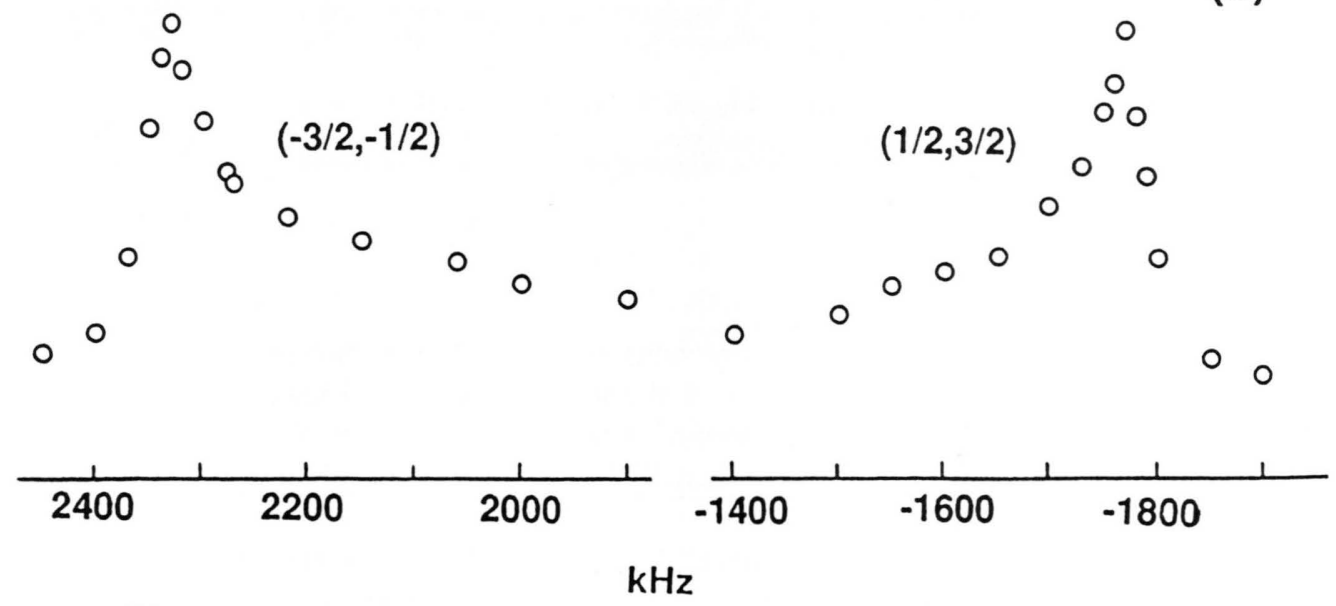

$\circ 0$

$0^{0}$

$\mathrm{kHz}$

(b)

Fig. 14. ${ }^{139} \mathrm{La}$ frequency-stepped spin echo NQR spectrum for $\mathrm{La}_{2} \mathrm{O}_{3} ;$ (a) $(-1 / 2,1 / 2)$ and $(\mathrm{B})(-3 / 2,-1 / 2)$ and $(1 / 2,3 / 2)$ transition. 
${ }^{71} \mathrm{Ga}(I=3 / 2)$

In many instances the electric field gradient at the $\mathrm{Ga}$ nucleus is sufficiently small that the quadrupolar parameters may be conveniently determined by high field MAS NMR using, in general, the isotope ${ }^{71} \mathrm{Ga}$, which has lower abundance than ${ }^{69} \mathrm{Ga}$ but has the advantage for NMR of lower quadrupole moment and a higher Lamor frequency. The MAS spectrum for ${ }^{71} \mathrm{Ga}$ in $\mathrm{LiGaO}_{2}$ (Fig. 9) shows the sharpness of detail which can be obtained and the consequent precision of the $C_{q}$ and $\eta$ values.

\section{${ }^{91} \mathrm{Zr}(I=5 / 2)$}

The various forms of zirconium oxide, $\mathrm{ZrO}_{2}$, viz. monoclinic, tetragonal, orthorhombic and cubic, have been characterised in dense solid ceramic specimens by ${ }^{91} \mathrm{Zr}$ NMR [10,11], using the technique of frequency stepped spin echoes to define the quadrupolar lineshape (Figure 10). These phases are the constituents of partially stabilised zirconia, which is a high strength, high toughness engineering ceramic. The interchange between the tetragonal phase and orthorhombic phases on cycling between $77 \mathrm{~K}$ and $600 \mathrm{~K}$ (Fig. 11), has been demonstrated [11]. The values of $C_{q}$ and $\eta$ were determined for these four phases by simulation.

Using the same technique, zirconium metal [10] and the materials $\mathrm{Na}_{2} \mathrm{ZrO}_{3}$ [3], $\mathrm{Na}_{2} \mathrm{ZrSiO}_{5}$ [12] and $\mathrm{ZrF}_{4}$ (Fig. 12) have been similarly characterised by ${ }^{91} \mathrm{Zr}$ NMR.

\section{${ }^{93} \mathrm{Nb}(I=9 / 2)$}

Although the $C_{q}$ values for many niobium compounds are sufficiently large to require either NQR or frequency stepped echo spectroscopy to obtain their quadrupole interaction parameters, the octahedral coordination of the niobates which have the perovskite structure can result in coupling constants which may be determined by conventional pulsed FT NMR. A $C_{q}$ value for ${ }^{93} \mathrm{Nb}$ has been previously obtained by NQR at $77 \mathrm{~K}$ [13]. Figure 13 shows the MAS NMR spectrum for $\mathrm{LiNbO}_{3}$ for which $\eta=0$. The value $C_{q}=22.9$ $\mathrm{MHz}(296 \mathrm{~K})$ obtained by simulation agrees well with the NQR value of $C_{q}=22.52 \mathrm{MHz}(77 \mathrm{~K})$.

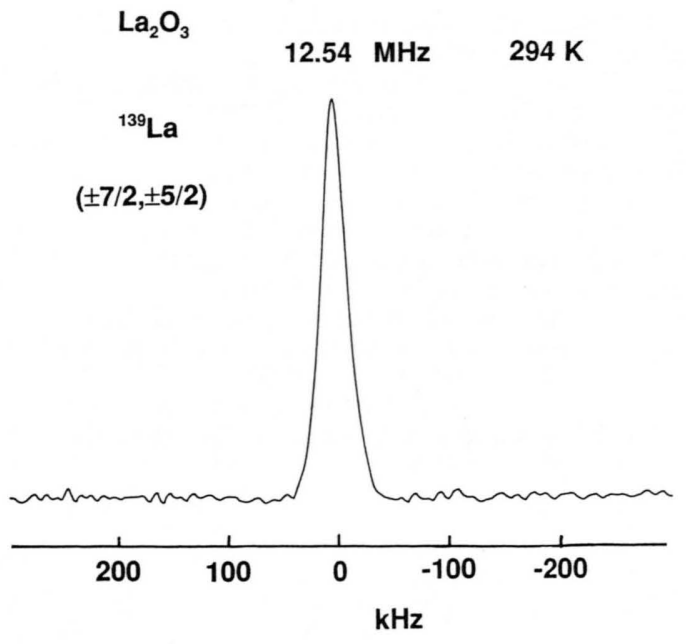

Fig. 15. ${ }^{139} \mathrm{La}( \pm 7 / 2, \pm 5 / 2) \mathrm{NQR}$ transition for $\mathrm{La}_{2} \mathrm{O}_{3}$. The zero of the frequency scale corresponds to the spectrometer frequency of $12.53 \mathrm{MHz}$.

${ }^{139} \mathrm{La}(I=7 / 2)$

The perovskites $\mathrm{LaMO}_{3}$ (where $\mathrm{M}$ is a first row transition metal) may be doped with divalent metal oxides to exhibit a wide range of magnetic and electrical properties [14]. Doping with $\mathrm{SrO}_{2}$ can produce metallic and ordered magnetic states (ferromagnetic or antiferromagnetic). A current use for such compounds is as high temperature electrodes in fuel cells.

These compounds, with $\mathrm{M}=\mathrm{Cr}$, Co and $\mathrm{Mn}$, in both the pure form and doped wth $\mathrm{SrO}_{2}$, and also the basic starting material $\mathrm{La}_{2} \mathrm{O}_{3}$, have been characterised by ${ }^{139}$ La NMR using frequency stepped spin echoes to define the quadrupole perturbed lineshape [15]. The quadrupolar lineshape has been used to estimate the percentage success of a solid state powder preparation of $\mathrm{SrO}_{2}$ doped lanthanum chromite $\left(\mathrm{LaCrO}_{3}\right)$. Lanthanum manganite $\left(\mathrm{LaMnO}_{3}\right)$ in both the doped and undoped form exhibits strong magnetic hyperfine effects in the spectra.

The ${ }^{139} \mathrm{La}$ coupling constant for hexagonal $\mathrm{La}_{2} \mathrm{O}_{3}$ could be determined, with increasing accuracy, from the second order broadened $(-1 / 2,1 / 2)$ pattern (Fig. 14a), the spacing between the first order $\left(\Theta=90^{\circ}\right)$ singularities for the $(-3 / 2,-1 / 2)$ and $(1 / 2$, $3 / 2$ ) transitions (Fig. 14b) and finally the zero field $( \pm 7 / 2, \pm 5 / 2)$ NQR transition (Figure 15). 
[1] T. J. Bastow, M. E. Smith, and H. J. Whitfield, J. Mater. Chem. 2, 989 (1992).

[2] T. J. Bastow, A. F. Moodie, M. E. Smith, and H. J. Whitfield, J. Mater. Chem. 3, 697 (1993).

[3] T. J. Bastow, M. E. Smith, and H. J. Whitfield, Solid State Nuclear Magnetic Resonance (in press).

[4] C. Gabathuler, E. E. Hundt, and E. Brun, Magnetic Resonance and Related Phenomena, Proceedings of the 17th Congress Ampère, Turku, ed. V. Hovi; North-Holland, Amsterdam 1973, pp. 499-501.

[5] M. E. Smith, Appl. Magntic Resonance 4, 1 (1993).

[6] M. E. Smith and S. Steuernagel, Solid State Nuclear Magnetic Resonance, 1, 175 (1992).

[7] T. J. Bastow, J. Chem. Soc. Faraday Trans. (1992).

[8] I. J. F. Poplett and J. A. S. Smith, J. Chem.Soc. Faraday Trans. 2, 77, 1155 (1981).
[9] D. Abramic, J. Seliger, V. Zagar, and R. Blinc, J. Phys.: Condens. Matter 5, 3373 (1993).

[10] T. J. Bastow, M. E. Smith, and S. N. Stuart, Chem. Phys. Lett. 191, 125 (1992).

[11] T. J. Bastow and M. E. Smith, Solid State NMR 1, 165 (1992).

[12] T. J. Bastow (unpublished data).

[13] E. F. Schempp, G. E. Peterson, and J. R. Carruthers, J. Chem. Phys. 53, 306 (1970).

[14] F. Galasso, Structure, Properties and Preparation of Perovskite-type Compounds, Pergamon, Oxford 1969.

[15] T. J. Bastow, Solid State Nuclear Magnetic Resonance (in press). 